\title{
Fuzzy Evaluation of Physical Education Teaching Quality in Colleges Based on Analytic Hierarchy Process
}

\author{
https://doi.org/10.3991/ijet.v16i06.21097 \\ Xiaokun Zhao, Chao Zheng $(\bowtie)$ \\ Tangshan University, Hebei, China \\ ztang191z@126.com
}

\begin{abstract}
For physical education (PE) in colleges, the evaluation of the teaching quality is affected by various fuzzy and uncertain factors. Therefore, this paper probes deep into the fuzzy evaluation of the teaching quality of college PE, using analytic hierarchy process (AHP), fuzzy system theory and grey theory. Firstly, the factors affecting the teaching quality of college PE were analyzed theoretically, and the keys to improving that teaching quality were clarified. On this basis, the authors established an evaluation index system and a fuzzy evaluation model for the teaching quality of college PE. The proposed fuzzy evaluation model serves an innovative tool to evaluate the teaching quality of college PE. Apart from effective measurement of the teaching quality, the proposed model provides an important reference for improving the teaching quality of college PE.
\end{abstract}

Keywords - Teaching quality; physical education (PE), colleges, analytic hierarchy process (AHP), fuzzy evaluation

\section{$1 \quad$ Introduction}

Modern higher education attaches great importance to students' comprehensive quality, it aims not only to train them to have a solid professional knowledge reserves, but also explore their potentials in their professions; especially during the implementation of quality education, the training of comprehensive quality has become particularly important, and the requirement for such training is now an urgent need in modern society [1-3]. As an important part of modern education, PE has an irreplaceable role in the training of sports talents, and modern education is laying more emphasis on PE than ever before [4-6]. To training high-quality sports professionals, the PE major itself needs to have a high-level teaching quality, and at the same time, only by effectively evaluating and analyzing this teaching quality can we provide a good support for the improvement of the teaching quality of college PE major. For example, XU elaborated on the main factors affecting the improvement of the teaching quality of $\mathrm{PE}$ lessons and analyzed relevant measures and strategies, providing a theoretical basis for the improvement of PE quality. MA analyzed teaching quality evaluation systems for college PE and proposed a few optimization strategies [8]. FAN et al. took the special course of dancesport in colleges and universities as an example to 
research the PE teaching quality using a factor-based analysis method [9]. Chen et al. analyzed the teaching quality evaluation of young PE teachers and provided a reference for the improvement of PE quality [10]. However, since fuzzy and uncertain information is often involved in the evaluation process, the teaching quality evaluation of college PE is fuzzy and complex. For such system decision-making problems, there're a few existing research results [11-14], but due to the complexity and professional features of college PE, how to design an evaluation system and an evaluation model that are suitable for the teaching quality of college PE is of very important research significance. To this end, based on existing research results, this paper probes deeper into relevant theories and adopted AHP [15-16], fuzzy system theory [17-18] and grey theory [19-20] to improve a fuzzy evaluation model for the teaching quality of college PE.

The research content of this paper consists of 5 parts: the first part is an overview of the researches concerning the teaching quality of college PE; the second part analyzes the key factors; the third part establishes a new evaluation system; the fourth part proposes an improved fuzzy evaluation model and gives the algorithm; and the fifth part is the conclusion.

\section{Key Factors Affecting the Teaching Quality of College PE}

\subsection{Teaching concept}

College PE is an important part in higher education and a key link in the implementation of quality education. It aims to train high-quality sports talents by imparting professional sports knowledge, expanding their vision of the profession, and improving their comprehensive quality. The development of higher education shares the features of the times; therefore, its ultimate purpose is to meet the requirements of social development. Now, with the progress of social development, the demands for sports professionals are becoming increasingly urgent, and this calls for an advanced teaching concept to support college PE and make sure that it is heading towards a right, scientific, reasonable, and opportune direction, and this is also a prerequisite for the cultivation of high-quality sports professionals. This paper proposes the following aspects to pledge an advanced teaching concept for college PE, the first thing is to construct a good and scientific teaching model for college PE and do a good job in organizing the teaching activities; the second is to choose the right and advanced teaching tools for college PE; and the third is to design formal and intelligent teaching forms and carry out them effectively.

\subsection{Resource input}

The teaching quality of college PE is affected by various resources (factors) such as manpower, materials, and money, and how to allocate these resources to match with the sports talent cultivation goals and plans of colleges and universities is a system decision-making project that requires scientific and reasonable arrangement, 
planning, utilization and optimization of various teaching resources. This paper holds that, to improve the manpower input in college PE, three kinds of personnel should be introduced, namely high-quality professional teachers, high-level teaching administrators, and excellent student source of sports major. In terms of the material factor, the input in sports venue construction, basic facilities, training equipment, sports research offices, training centers, and sports teaching and research programs should be increased. This is because the allocation of the teaching resources has an important impact on the improvement of the teaching quality of college PE, proper resource allocation can promote the improvement of the teaching quality of college PE, while improper resource allocation would seriously hinder the improvement of such quality.

\subsection{Teaching scheme}

The planning of PE teaching scheme means the design of the specific teaching content of college PE lessons, mainly including the syllabus formulation, textbook compilation and selection, curriculum construction, excellent course design and teaching task planning, etc. A good teaching scheme is a basic guarantee for the cultivation of sports professionals, and only by formulating a set of scientific, reasonable, and suitable teaching scheme can the cultivated sports talents have high quality and better fit the requirement of the times.

\subsection{Faculty level}

A college with a high-level PE faculty would have strong competitiveness in sports lesson teaching, which lays a solid foundation for the cultivation of sports talents. Then, as the school's reputation and competitiveness are growing, the quality of student source would be improved, and thus forming a good development process of college PE, therefore the faculty level has an irreplaceable role in the cultivation of sports talents. On the contrary, a college with a low-level PE faculty would have incompetent teaching ability and low teaching level, which can result in low-quality student source, in the long run, the teaching quality of college PE would be of inferior quality. Therefore, the PE faculty level is a basic condition for the cultivation of sports professionals and sports major graduates, and thus enhancing the PE faculty level is of great significance for the improvement of the teaching quality of college PE. One more thing, to enhance the PE faculty level, two aspects are worth notice, one is the introduction of senior professional PE teachers, the other is the training of young teachers, in this way, a good PE faculty with talent hierarchies could be formed.

\subsection{Teaching effect}

The teaching effect of PE lessons is a direct manifestation of PE quality, it reflects not only the teaching ability of PE teachers, but also the learning effect of sports students; therefore, improving the teaching effect of PE lessons is an important condition for the improvement of the teaching quality of college PE, and to achieve such im- 
provement, we must do a good job in the teaching activities in PE lessons. In terms of the teaching of PE lessons, it can be divided into two parts: the teaching of theory and the teaching of practice, and these two have their respective teaching contents, goals, and tasks, and their requirements for teaching tools, environment, and classroom atmosphere are different as well, and all these aspects would have an impact on the teaching effect of PE lessons. Therefore, this paper proposes that, to do well in the teaching of PE lessons, first, proper teaching tools should be selected to form a good teaching environment; then, in the teaching process, the professional sports knowledge must be lectured systematically, key knowledge points should be highlighted for students; as for the technical movements, efforts should be made to make the skills more teachable, such as increasing interaction links in the classroom teaching, and fully mobilizing students' learning initiative and enthusiasm.

\subsection{Intelligent tools}

Nowadays, various intelligent technologies are developing rapidly, and they have penetrated into the field of higher education, urging the emergence of diverse intelligent tools for higher education; technologies such as AI, Internet, information technology and VR have accelerated the development of intelligent education tools and platforms, as a result, multimedia education, digital education, online education, and other education forms have appeared and are developing continuously. Moreover, with the support of these intelligent technologies, the teaching methods and tools are also being improved to varying degrees, which has an important role in improving the teaching efficiency and teaching level. The teaching process of PE lessons includes both the teaching of theoretical knowledge and the teaching of practice, it needs to be conducted both indoor and outdoor, therefore, the requirements for intelligent teaching tools and techniques are more diversified and urgent. By adopting intelligent teaching tools, PE teachers can impart professional knowledge more systematically, enrich the knowledge reserves of sports students, expand their professional vision, enlarge their learning scope, as well as more intelligently and directly show the technical moves that are hard to understand and master, which is conductive for sports students to grasp the key points and difficult points in learning, and thereby achieving the results of improving the teaching quality of college PE.

\subsection{Management system and reward mechanism}

The teaching management system and reward mechanism is another important factor affecting the teaching quality of college PE. As we all know, besides that the development of education must be in line with the social requirements, it also needs certain orientation, and such orientation should be guided by a good teaching management system and a reasonable reward and punishment mechanism. In terms of PE, teaching management system and reward mechanism can regulate teaching behaviors and activities during the teaching process, and in the meantime, they can motivate PE teachers and students to participate in the teaching and learning of PE lessons. A good teaching management system and a reasonable reward mechanism can urge PE to 
develop in the right direction, while an unsound teaching management system and unreasonable reward mechanism will throw PE into chaos. Therefore, in order to ensure the smooth implementation of the teaching activities of college PE and obtain high-level teaching quality, it's necessary to improve the teaching management system and the reward mechanism of college PE.

\section{Construction of a New Quality Evaluation System for College PE}

\subsection{Methods}

A variety of methods such as induction method, questionnaire survey, expert consultation, and statistical analysis were adopted and combined to construct the new quality evaluation system for college PE. Through induction method, research literatures concerning the topic of college PE teaching quality were summarized and analyzed, which provided theoretical support for the evaluation system to be constructed in the paper. Through questionnaire survey, criterions of the PE teaching quality evaluation of different objects were investigated and key evaluation indices were extracted. Through expert consultation, the selected evaluation indices were optimized to make them more in line with the objective conditions. Through statistical analysis, a few fuzzy evaluation indices were analyzed and processed to get reliable original data for the evaluation of the teaching quality of college PE.

\subsection{Principles for evaluation index selection}

The selection of evaluation indices of college PE teaching quality should comprehensively consider the objective conditions and influencing factors from multiple aspects and levels, and the selected evaluation indices must be scientific, practical and reliable. For this reason, this paper holds that the selection of evaluation indices of college PE teaching quality needs to follow the following principles: first, the scientific principle, that is, the selected evaluation indices should have clear and specific scientific meanings and be able to reflect the essential content of the evaluation of college PE teaching quality, and they should have reasonable logic. Second, the selected evaluation indices must be real and objective, that is, they should be able to reflect the true and objective conditions of the evaluation of college PE teaching quality, and have real meanings; the evaluation indices must not be subjective or made-up. Third, the selected evaluation indices should be comprehensive and able to reflect the essential problems of the evaluation in an all round way. Fourth, the selected evaluation indices should be operable, that is, it should be easy to calculate and analyze these indices. 


\subsection{Hierarchies of the evaluation system}

The evaluation system of college PE teaching quality is a multi-layer structure, including the system layer, the criterion layer, and the index layer. The system layer refers to the college PE teaching quality evaluation system to be constructed; the criterion layer contains the evaluation criterions to be followed; and the index layer includes specific evaluation indices under each criterion. The hierarchical structure of the evaluation system of the teaching quality of college PE is shown in Figure 1 below.

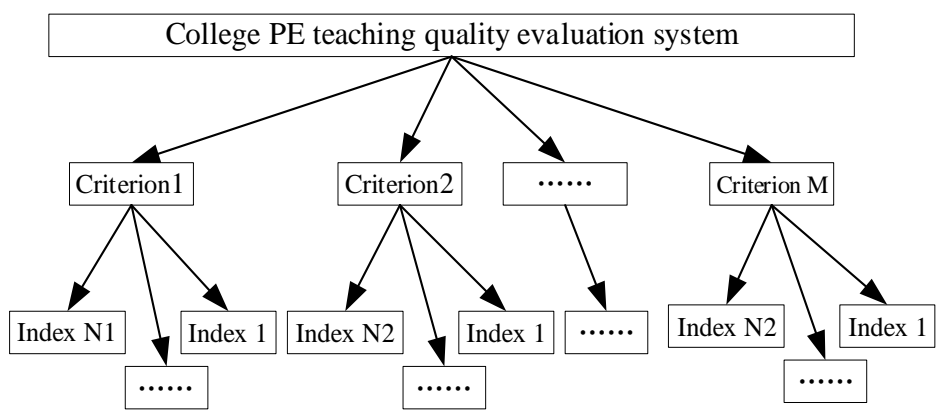

Fig. 1. Hierarchies of college PE teaching quality evaluation system

\subsection{Establishment of the evaluation system}

Based on the above discussion, this paper proposes 5 criterions for the said system, namely professional quality, teaching content, teaching method, teaching reform, and teaching effect. The professional quality of PE teachers is a key feature reflecting the teaching ability of PE lessons, having a high-level PE faculty and professional PE teachers is conductive to the cultivation of college PE students. The teaching content offers the knowledge source for the cultivation of college PE students; it is a basis of the knowledge reserves of college students. The teaching method is an important guarantee for the transmission of sports knowledge, and advanced PE teaching methods are very helpful to the improvement of the teaching quality of college PE. The teaching reform acts as a catalyst to accelerate the development of college PE, so that it could keep up with the development of the times. The teaching effect is a direct manifestation of the teaching quality of college PE. In conclusion, the structure and detailed content of the evaluation system are shown in Table 1 below. 
Paper-Fuzzy Evaluation of Physical Education Teaching Quality in Colleges Based on Analytic...

Table 1. Structure and content of college PE teaching quality evaluation system

\begin{tabular}{|c|c|c|}
\hline System layer & Criterion layer & Index layer \\
\hline \multirow{32}{*}{$\begin{array}{l}\text { College PE teaching } \\
\text { quality evaluation } \\
\text { system }\end{array}$} & \multirow{4}{*}{$\begin{array}{l}\text { Professional } \\
\text { quality } \\
\text { of PE teaching }\end{array}$} & Number of PE teachers with senior professional titles \\
\hline & & Teaching level of PE teachers \\
\hline & & Ratio of loss to introduction of senior PE teachers \\
\hline & & Teaching planning ability \\
\hline & \multirow{4}{*}{ Teaching content } & The teaching content of PE lessons is up-to-date \\
\hline & & The teaching content of PE lessons is rich \\
\hline & & Key teaching content is highlighted \\
\hline & & The teaching content of PE lessons is professional \\
\hline & \multirow{7}{*}{ Teaching method } & The teaching method of PE teaching is proper and reasonable \\
\hline & & Ability to teach students in accordance with their aptitude \\
\hline & & The teaching method matches the teaching content \\
\hline & & The teaching method can motivate students' learning enthusiasm \\
\hline & & The teaching tasks are controllable \\
\hline & & The teaching goals are achievable \\
\hline & & The teaching plans are organized \\
\hline & \multirow{6}{*}{ Teaching reform } & The teaching mode is innovative \\
\hline & & Integration of industry-university-research \\
\hline & & Conversion of sports knowledge \\
\hline & & Adaptability of teaching management \\
\hline & & Number of high-level teaching reform programs undertaken \\
\hline & & Number of high-level teaching reform rewards received \\
\hline & \multirow{11}{*}{ Teaching effect } & Excellent rate of PE students \\
\hline & & Loss rate of PE students \\
\hline & & Skill level of PE students \\
\hline & & Technical movement mastery of PE students \\
\hline & & Autonomous learning ability of PE students \\
\hline & & Innovation ability of PE students \\
\hline & & Physical fitness of PE students \\
\hline & & Employment rate of PE students \\
\hline & & Social satisfaction \\
\hline & & Adaptability of PE students \\
\hline & & Coordination ability of PE students \\
\hline
\end{tabular}

\section{$4 \quad$ Fuzzy Evaluation Model and its Algorithm}

\subsection{Initial data acquisition and normalization of evaluation indices}

Based on the above-established evaluation system, the questionnaire survey results and the statistical analysis results, the initial data of each evaluation index of the evaluation object could be obtained. Since some indices are qualitative, their initial data are fuzzy data; some indices are quantitative, their initial data may be accurate or fuzzy, and the scales of these evaluation indices are different as well, therefore, these indices need to be normalized. 
From the perspective of fuzzy evaluation, for the $k$-th evaluation object $P$, the initial data of the j-th teaching quality evaluation index is $R_{k j}(P)=\left[r_{k j}^{L e f}(P), r_{k j}^{R i g}(P)\right]$, $r_{k j}^{L e f}(P) \leq r_{k j}^{R i g}(P)$. If the $\mathrm{j}$-th evaluation index is a positive index, then its normalized data $U_{k j}(P)$ is:

$$
\begin{aligned}
& U_{k j}(P)=\left[u_{k j}^{L e f}(P), u_{k j}^{R i g}(P)\right] \\
& =\left[\frac{r_{k j}^{L e f}(P)-\min _{1 \leq k \leq K} r_{k j}^{L e f}(P)}{\max _{1 \leq k \leq K} u_{k j}^{R i g}(P)-\min _{1 \leq k \leq K} r_{k j}^{L e f}(P)}, \frac{r_{k j}^{R i g}(P)-\min _{1 \leq k \leq K} r_{k j}^{L e f}(P)}{\max _{1 \leq k} u_{k j}^{R i g}(P)-\min _{1 \leq k \leq K} r_{k j}^{L e f}(P)}\right]
\end{aligned}
$$

where, $K$ represents the number of evaluation objects, $n$ represents the number of evaluation indices, and $1 \leq j \leq n, 1 \leq k \leq K$.

If the $j$-th evaluation index is a negative index, its normalized data $U_{k j}(P)$ is:

$$
\begin{aligned}
& U_{k j}(P)=\left[u_{k j}^{L e f}(P), u_{k j}^{R i g}(P)\right] \\
& =\left[\frac{\max _{1 \leq k \leq K} u_{k j}^{R i g}(P)-r_{k j}^{R i g}(P)}{\max _{1 \leq k \leq K} u_{k j}^{R i g}(P)-\min _{1 \leq k \leq K} r_{k j}^{L e f}(P)}, \frac{\max _{1 \leq k \leq K} u_{k j}^{R i g}(P)-r_{k j}^{L e f}(P)}{\max u_{k j}^{R i g}(P)-\min _{1 \leq k \leq K} r_{k j}^{L f f}(P)}\right]
\end{aligned}
$$

\subsection{The weight of evaluation index}

Generally, different evaluation indices have different contributions to the evaluation result; so their weight values are different as well. Since there are a few qualitative indices in this problem, and the AHP is a reliable and easy-to-calculate method that is suitable for solving complex system decision-making problems and it can realize quantitative analysis of qualitative problems [21-22], it had been adopted to analyze the weight of these evaluation indices.

Experts engaged in the field were invited to score the evaluation indices in pairs, and the score values were judged using 1-9 ratios. Greater score value $b_{i j}$ indicates greater importance, namely greater weight value, the size of score value $b_{i j}$ and the corresponding meanings are shown in Table 2.

Table 2. Value of $b_{i j}$ and its meanings

\begin{tabular}{|c|l|}
\hline $\boldsymbol{b}_{i j}$ & \multicolumn{1}{c|}{ Meanings } \\
\hline 1 & The two evaluation indices are of equal importance \\
\hline 3 & The former evaluation index is slightly more important \\
\hline 5 & The former evaluation index is more important \\
\hline 7 & The former evaluation index is much more important \\
\hline 9 & The former evaluation index is extremely more important \\
\hline $2,4,6,8$ & Middle state between two adjacent states mentioned-above \\
\hline$b_{j i}=1 / b_{i j}$ & The importance of the latter evaluation index with respect to the former one \\
\hline
\end{tabular}


Under the condition that the score values of any two evaluation indices are obtained, the judgment matrix $\boldsymbol{B}$ of the evaluation indices of the teaching quality of college PE could be constructed as follows:

$$
\mathbf{B}=\left[\begin{array}{ccccc}
b_{11} & \cdots & b_{1 j} & \cdots & b_{1 n} \\
\vdots & \vdots & \vdots & \vdots & \vdots \\
b_{i 1} & \cdots & b_{i j} & \cdots & b_{i n} \\
\vdots & \vdots & \vdots & \vdots & \vdots \\
b_{n 1} & \cdots & b_{n j} & \cdots & b_{n n}
\end{array}\right]
$$

By calculating this matrix, its maximum eigenvalue $\lambda_{\max }(\boldsymbol{B})$ and the corresponding eigenvector $W(\mathbf{B})$ could be obtained, and then the consistency index $C I_{B}$ of the judgment matrix $\boldsymbol{B}$ could be obtained as:

$$
C I_{\mathbf{B}}=\frac{\lambda_{\max }(\mathbf{B})-n}{n-1}
$$

According to $\boldsymbol{n}$, the number of evaluation indices under in a same layer, by looking up reference tables, the value of average random consistency index $R I$ could be obtained as shown in Table 3.

Table 3. Value of $R I$

\begin{tabular}{|l|l|l|l|l|l|l|l|l|l|l|} 
Number of evaluation indices $\mathbf{n}$ & $\mathbf{1}$ & $\mathbf{2}$ & $\mathbf{3}$ & $\mathbf{4}$ & $\mathbf{5}$ & $\mathbf{6}$ & $\mathbf{7}$ & $\mathbf{8}$ & $\mathbf{9}$ & $\mathbf{1 0}$ \\
\hline
\end{tabular}

\begin{tabular}{|c|c|c|c|}
\hline 0 & 0 & 0.58 & \\
\hline
\end{tabular}
RI

Then, the consistency index $C R_{B}$ could be obtained as:

$$
C R_{\mathrm{B}}=C I_{\mathrm{B}} / R I
$$

If $C R_{B}<0.1$, it means that the judgment matrix $\mathbf{B}$ has good consistency, and the weight $w_{i}$ of the $i$-th evaluation index is:

$$
w_{i}=\frac{\sum_{j=1}^{n} b_{i j}}{\sum_{i=1}^{n} \sum_{j=1}^{n} b_{i j}}
$$

If $C R_{B}<0.1$ is not satisfied, it indicates that the consistency of judgment matrix $\mathbf{B}$ does not meet the requirements, and judgment and analysis need to be performed again. 


\subsection{Fuzzy evaluation model}

In order to effectively deal with the fuzzy and uncertain information in the evaluation process, the evaluation indices were processed according to the fuzzy system theory. For the j-th evaluation index, after all evaluation objects were subject to normalization, the optimal fuzzy value $U_{j}(P)$ of the $\mathrm{j}$-th evaluation index could be obtained:

$$
\begin{aligned}
& U_{j}(P)=\left[u_{j}^{L e f}(P), u_{j}^{R i g}(P)\right] \\
& =\left[\max _{1 \leq k \leq K} u_{k j}^{L e f}(P), \max _{1 \leq k \leq K} u_{k j}^{R i g}(P)\right]
\end{aligned}
$$

And it satisfies $u_{j}^{\text {Lef }}(P) \leq u_{j}^{\text {Rig }}(P)$.

According to the calculation model of fuzzy distance [23-24], for the k-th evaluation object $\boldsymbol{P}$, the Euclidean distance $D_{k j}^{\Omega}(P)$ between the j-th evaluation index and its corresponding optimal fuzzy value $U_{j}(P)$ is:

$$
D_{k j}^{\Omega}(P)=\sqrt{\left(\left|u_{k j}^{L e f}(P)-u_{j}^{L e f}(P)\right|^{2}+\left|u_{k j}^{R i g}(P)-u_{j}^{R i g}(P)\right|^{2}\right) / 2}
$$

The smaller the value of $D_{k j}^{\Omega}(P)$, the closer the distance between the j-th evaluation index and its corresponding optimal fuzzy value $U_{j}(P)$, and vice versa. Here, the fuzzy correlation between the k-th evaluation object $\boldsymbol{P}$ with respect to the i-th evaluation index and its corresponding optimal fuzzy value $U_{j}(P)$ is introduced as:

$$
\phi_{k j}^{\Omega}(P)=1-D_{k j}^{\Omega}(P)
$$

\subsection{Grey evaluation model}

In order to effectively deal with the gray uncertain information in the evaluation process, the evaluation indices were processed according to the gray theory [25-27]. For the k-th evaluation object $\boldsymbol{P}$, its corresponding evaluation index comparison sequence $\boldsymbol{U}_{k}(P)$ can be established as:

$$
\mathbf{U}_{k}(P)=\left\{U_{k 1}(P), U_{k 2}(P), \cdots, U_{k j}(P), \cdots, U_{k n}(P)\right\}
$$

Similarly, for all K evaluation object $\boldsymbol{P}$, the reference sequence $\mathrm{U}(P)$ can be established as:

$$
\mathbf{U}(P)=\left\{\max _{1 \leq k \leq K} U_{k 1}(P), \max _{1 \leq k \leq K} U_{k 2}(P), \cdots, \max _{1 \leq k \leq K} U_{k j}(P), \cdots, \max _{1 \leq k \leq K} U_{k n}(P)\right\}
$$

According to the grey correlation analysis, for the k-th evaluation object $\boldsymbol{P}$, the gray correlation coefficient $\eta_{k j}^{\Omega}(P)$ of comparison sequence $\boldsymbol{U}_{k}(P)$ and reference sequence $\mathrm{U}(\mathrm{P})$ with respect to the $\mathrm{i}$-th evaluation index is: 


$$
\eta_{k j}^{\Omega}(P)=\frac{\min _{k} \min _{j} d_{k j}^{\Omega}(P)+\beta \max _{k} \max _{j} d_{k j}^{\Omega}(P)}{d_{k j}^{\Omega}(P)+\beta \max _{k} \max _{j} d_{k j}^{\Omega}(P)}
$$

where, $\beta$ is the identification coefficient, its value is between 0 and 1 , generally takes $\beta=0.5$. And there is:

$$
d_{k j}^{\Omega}(P)=\frac{\left|u_{j}^{R i g}(P)-u_{k j}^{R i g}(P)\right|+\left|u_{j}^{L e f}(P)-u_{k j}^{L e f}(P)\right|}{2}
$$

\subsection{Construction of the comprehensive evaluation model}

With the weight values of the evaluation indices taken into account, the weighted fuzzy correlation $\varphi_{k}^{\Omega}(P)$ between the $k$-th evaluation object $\boldsymbol{P}$ and the optimal fuzzy value $U_{j}(P)$ could be constructed as:

$$
\varphi_{k}^{\Omega}(P)=\sum_{j=1}^{n}\left(w_{j} \times \phi_{k j}^{\Omega}(P)\right)
$$

where, $w_{j}$ represents the weight of the $\mathrm{j}$-th evaluation index.

Similarly, the weighted gray correlation $\psi_{k}^{\Omega}(P)$ between the $k$-th evaluation object $\boldsymbol{P}$ and the reference sequence $\boldsymbol{U}(P)$ could be constructed as:

$$
\psi_{k}^{\Omega}(P)=\sum_{j=1}^{n}\left(w_{j} \times \eta_{k j}^{\Omega}(P)\right)
$$

Thus, the comprehensive correlation of $\zeta_{k}^{\Omega}(P)$ the $k$-th evaluation object $\boldsymbol{P}$ is:

$$
\zeta_{k}^{\Omega}(P)=\alpha_{1} \times \varphi_{k}^{\Omega}(P)+\alpha_{2} \times \psi_{k}^{\Omega}(P)
$$

where, $\alpha_{1}$ and $\alpha_{2}$ respectively represent the percentage of fuzzy uncertain information and the percentage of gray information in the evaluation process.

If it satisfies:

$$
\zeta_{g}^{\Omega}(P)=\max \left\{\zeta_{1}^{\Omega}(P), \zeta_{2}^{\Omega}(P), \cdots, \zeta_{k}^{\Omega}(P), \cdots, \zeta_{K}^{\Omega}(P)\right\}
$$

where, $1 \leq g \leq K$.

It indicates that the college PE teaching quality of the g-th evaluation object $\boldsymbol{P}$ is the best.

\section{Conclusion}

This paper conducted an in-depth analysis on the key factors affecting the teaching quality of college PE and pointed out the connotations of the improvement of college 
PE teaching quality. Then, on this basis, the paper researched the evaluation system and the fuzzy evaluation model of college PE teaching quality, and discussed key content such as evaluation index selection, data processing, weight analysis, fuzzy decision-making, and gray correlation analysis, etc.; moreover, the paper established a novel evaluation model and an improved fuzzy evaluation model for the teaching quality of college PE. The research results provide a theoretical reference for the improvement of college PE teaching quality, and it is of certain application value.

\section{$6 \quad$ References}

[1] Beschkova, E.F. (2020). Research on the Potential Education Space for the Development of College Students' Physical Education in Russian Comprehensive Universities. Journal of Capital University of Physical Education and Sports, 32(4): 289-291. https://doi.org/10. 14036/j.cnki.cn11-4513.2020.04.001

[2] Liu, P. (2019). Research on the quality education of college students and the reform of College Physical Education Curriculum. Science \& Technology of Stationery \& Sporting Goods, (14): 89-90. https://doi.org/10.3969/j.issn.1006-8902.2019.14.042

[3] Gao, K. (2020). The Strategy Analysis of Promoting College Students' Extracurricular Sports Activities. Contemporary Sports Technology, 10(25): 83-85. https://doi.org/ 10. 16655/j.cnki.2095-2813.2001-5352-8974

[4] Han, K. (2020). Evaluation of teaching quality of college physical education based on analytic hierarchy process, International Journal of Emerging Technologies in Learning, 15(10): 86-99. https://doi.org/10.3991/ijet.v15i10.14039

[5] Liu, R.Q., Shi, M.G. (2019). Mengguang. Research on physical education teaching environment in Colleges and universities in China. Contemporary Sports Technology, 9(30): 123-124. https://doi.org/10.16655/j.cnki.2095-2813.2019.30.123

[6] Kubiyeva, S., Akhmetova, A., Islamova, K., Aralbayev, A., Sholpankulova, G. (2020). Electronic physical education textbook: Effective or not? Experimental study. International Journal of Emerging Technologies in Learning, 15(15): 64-78. https://doi.org/10.3991/ ijet.v15i15.14273

[7] Xu, X.M. (2019). Review on the Influence of Core Literacy Guidance on the Improvement of Physical Education Quality. Advances in Physical Sciences, 7(2): 58-61. https://doi. org/10.12677/APS.2019.72007

[8] Ma, Y.P., Sun, Z.W. (2020). Research on the evaluation system of College Physical Education Teaching Quality and the Optimization Strategy. Contemporary Sports Technology, 10(7): 91+93. https://doi.org/10.16655/j.cnki.2095-2813.2020.07.091

[9] Fan, M.M., Pan, Y.S. (2019). Research on teaching quality evaluation of sports dance special course in Independent College of Guangdong Province Based on factor analysis. Journal of Jilin TV \& Radio University, (6): 132-134. https://doi.org/ 10.3969/j.issn.10087508.2019.06.063

[10] Chen, P.S., Wu, G.Z. (2017). Teaching quality evaluation of young physical education teachers based on factor analysis. Journal of Chaohu College, 19(3): 125-129. https://doi.org/ 10.3969/j.issn.1672-2868.2017.03.023

[11] Chen, T. (2020). A fuzzy ubiquitous traveler clustering and hotel recommendation system by differentiating travelers' decision-making behaviors. Applied Soft Computing, 96: 1-10. https://doi.org/10.1016/j.asoc.2020.106585 
[12] Rivera-Niquepa, J.D., Jesus, P.M.D.O.D., Castro-Galeano, J.C., Hernandez-Torres, D. (2020). Planning stand-alone electricity generation systems, a multiple objective optimization and fuzzy decision making approach. Heliyon, 6(3): 1-12. https://doi.org/10. 1016/j.heliyon.2020.e03534

[13] Loganathan, A., Mani, I. (2018). A fuzzy based hybrid multi criteria decision making methodology for phase change material selection in electronics cooling system. Ain Shams Engineering Journal, 9(4): 2943-2950. https://doi.org/10.1016/j.asej.2017.11.005

[14] Shariat, R., Roozbahani, A., Ebrahimian, A. (2019). Risk analysis of urban stormwater infrastructure systems using fuzzy spatial multi-criteria decision making. Science of The Total Environment, 647: 1468-1477. https://doi.org/10.1016/j.scitotenv.2018.08.074

[15] Kheybari, S., Rezaie, F.M., Naji, S.A., Najafi, F. (2019). Evaluation of energy production technologies from biomass using analytical hierarchy process: The case of Iran. Journal of Cleaner Production, 232: 257-265. https://doi.org/10.1016/j.jclepro.2019.05.357

[16] Luca, S.D., Pace, R.D., Bruno, F. (2020). Accounting for attitudes and perceptions influencing users' willingness to purchase Electric Vehicles through a Hybrid Choice Modeling approach based on Analytic Hierarchy Process. Transportation Research Procedia, 45: 467-474. https://doi.org/10.1016/j.trpro.2020.03.040

[17] Gusmão, A.P.H., Silva, M.M., Poleto, T., Silva, L.C., Costa, A.P.C.S. (2018). Cybersecurity risk analysis model using fault tree analysis and fuzzy decision theory. International Journal of Information Management, 43: 248-260. https://doi.org/10.1016 /j.ijinfomgt.2018.08.008

[18] Mansouri, N., Zade, B.M.H., Javidi, M.M. (2019). Mohammad Masoud Javidi. Hybrid task scheduling strategy for cloud computing by modified particle swarm optimization and fuzzy theory. Computers \& Industrial Engineering, 130: 597-633. https://doi.org/10.1016/j.cie.2019.03.006

[19] Memon, M.S., Lee, Y.H., Mari, S.I. (2015). Sonia Irshad Mari. Group multi-criteria supplier selection using combined grey systems theory and uncertainty theory. Expert Systems with Applications, 42(21): 7951-7959. https://doi.org/10.1016/j.eswa.2015.06.018

[20] Bezuglov, A., Comert, G. (2016). Short-term freeway traffic parameter prediction: Application of grey system theory models. Expert Systems with Applications, 62: 284-292. https://doi.org/10.1016/j.eswa.2016.06.032

[21] Mandal, B., Mandal, S. (2018). Analytical hierarchy process (AHP) based landslide susceptibility mapping of Lish river basin of eastern Darjeeling Himalaya, India. Advances in Space Research, 62(11): 3114-3132. https://doi.org/10.1016/j.asr.2018.08.008

[22] Tshabalala, T., Ncube, B., Moyo, H.P. Abdel-Rahman E.M., Mutanga, O., Ndhlala, A.R. (2020). Predicting the spatial suitability distribution of Moringa oleifera cultivation using analytical hierarchical process modelling. South African Journal of Botany, 129: 161-168. https://doi.org/10.1016/j.sajb.2019.04.010

[23] Beaver, J.E., Dean, R.M. (2019). Using Euclidean distance in the comparative analysis of taxonomic abundance. Journal of Archaeological Science: Reports, 25: 331-340. https://doi.org/10.1016/j.jasrep.2019.03.022

[24] Djellab, M., Mehallegue, N., Achi, A. (2019). Use of Neumann series decomposition to fit the Weighted Euclidean distance and Inner product scoring models in automatic speaker recognition. Pattern Recognition Letters, 125: 500-507. https://doi.org/10.1016/j.patrec. 2019.06.013

[25] Gohil, V., Puri, Y.M. (2018). Optimization of Electrical Discharge Turning Process using Taguchi-Grey Relational Approach. Procedia CIRP, 68: 70-75. https://doi.org/10.1016/ j.procir.2017.12.024 
[26] Jaiprakash, M., Nagamadhu, M., Karthikeyan, K., Kiran, Shariff, M., Kumar, G.C.M. (2020). Effect of drilling parameters on Neem wood veneer epoxy composites using grey relational analysis. Materials Today: Proceedings, 24: 2163-2173. https://doi.org/10.1016/j.matpr.2020.03.674

[27] Abutu, J., Lawal, S.A., Ndaliman, M.B., Lafia-Araga, R.A., Adedipe, O., Choudhury, I.A. (2018). Effects of process parameters on the properties of brake pad developed from seashell as reinforcement material using grey relational analysis. Engineering Science and $\begin{array}{llll}\text { Technology, an International Journal, } & \text { 21(4): }\end{array}$ https://doi.org/10.1016/j.jestch.2018.05.014

\section{$7 \quad$ Authors}

Xiaokun Zhao was born in Tangshan City, Hebei Province, China in September 1980. He received a master's degree in physical education and training from the Sports Institute of Hebei Normal University in 2007. Now, he Worked at Tangshan University, Hebei Province 063000, China. His research is mainly the theoretical and technical analysis of sports teaching and training. He is a Chinese international physical fitness trainer.

Chao Zheng was born in Tangshan City, Hebei Province, China in July 1979. He received a master's degree in physical education and training from the Sports Institute of Hebei Normal University in 2012. Now, he Worked at Tangshan University, Hebei Province, China. His research is mainly the theoretical and technical analysis of sports teaching and training. He is a Chinese shot-put athlete.

Article submitted 2021-01-16. Resubmitted 2021-02-23. Final acceptance 2021-02-24. Final version published as submitted by the authors. 